\title{
Pattern of pesticide storage before pesticide self-poisoning in rural Sri Lanka

\author{
Fahim Mohamed ${ }^{* 1}$, Gamini Manuweera², David Gunnell ${ }^{3}$, Shifa Azher", \\ Michael Eddleston ${ }^{1,5}$, Andrew Dawson ${ }^{1}$ and Flemming Konradsen ${ }^{6}$
}

\begin{abstract}
Address: ${ }^{1}$ South Asian Clinical Toxicology Research Collaboration, Faculty of Medicine, University of Peradeniya, Sri Lanka, ${ }^{2}$ The Registrar of Pesticides, Government Department of Agriculture, Peradeniya, Sri Lanka, ${ }^{3}$ Department of Social Medicine, University of Bristol, Bristol, UK, ${ }^{4}$ Polonnaruwa General Hospital, North Central Province, Sri Lanka, ${ }^{5}$ National Poisons Information Service - Edinburgh, Royal Infirmary of Edinburgh, and Clinical Pharmacology Unit, University of Edinburgh, UK and ${ }^{6}$ Department of International Health, Immunology and Microbiology, University of Copenhagen, Copenhagen, Denmark
\end{abstract}

Email: Fahim Mohamed* - fahim@sactrc.org; Gamini Manuweera - gaminimanu@gmail.com; David Gunnell - D.J.Gunnell@bristol.ac.uk; Shifa Azher - contact@sactrc.org; Michael Eddleston - eddlestonm@yahoo.com; Andrew Dawson - ahdawson@gmail.com;

Flemming Konradsen - flko@sund.ku.dk

* Corresponding author

Published: 5 November 2009

BMC Public Health 2009, 9:405 doi: 10.1 I86/147/-2458-9-405

This article is available from: http://www.biomedcentral.com/I47/-2458/9/405

(C) 2009 Mohamed et al; licensee BioMed Central Ltd.

This is an Open Access article distributed under the terms of the Creative Commons Attribution License (http://creativecommons.org/licenses/by/2.0), which permits unrestricted use, distribution, and reproduction in any medium, provided the original work is properly cited.
Received: 24 July 2009

Accepted: 5 November 2009

\begin{abstract}
Background: Deliberate self-poisoning with agricultural pesticides is the commonest means of suicide in rural Asia. It is mostly impulsive and facilitated by easy access to pesticides. The aim of this large observational study was to investigate the immediate source of pesticides used for selfharm to help inform suicide prevention strategies such as reducing domestic access to pesticides.

Methods: The study was conducted in a district hospital serving an agricultural region of Sri Lanka. Patients who had self-poisoned with pesticides and were admitted to the adult medical wards were interviewed by study doctors following initial resuscitation to identify the source of pesticides they have ingested.
\end{abstract}

Results: Of the 669 patients included in the analysis, 425 (63.5\%) were male; the median age was 26 (IQR 20-36). In 5 II (76\%) cases, the pesticides had been stored either inside or immediately outside the house; among this group only eight patients obtained pesticides that were kept in a locked container. Ten percent $(n=67)$ of the patients used pesticides stored in the field while $14 \%$ $(n=91)$ purchased pesticides from shops within a few hours of the episode. The most common reasons for choosing the particular pesticide for self-harm were its easy accessibility $(n=31$ I, $46 \%)$ or its popularity as a suicide agent in their village $(n=290,43 \%)$.

Conclusion: Three quarters of people who ingested pesticides in acts of self-harm used products that were available within the home or in close proximity; relatively few patients purchased the pesticide for the act. The study highlights the importance of reducing the accessibility of toxic pesticides in the domestic environment. 


\section{Background}

Deliberate self harm is a major public health problem globally with an estimated 873,000 suicides in 2002 [1] and significant social and psychological impacts on affected families. In Asia, self-poisoning with pesticides, especially in rural areas, is a common means of self-harm and is associated with a high case fatality [2]. In countries such as China, Malaysia and Sri Lanka, $60 \%$ to $90 \%$ of all suicides are due to pesticide self-poisoning and it is estimated that there are between 250,000 to 370,000 suicides from pesticide poisoning worldwide every year [3].

Self-harm is often highly impulsive. Easy access to pesticides in and around the domestic environment in rural areas is believed to have made pesticide self-poisoning a preferred means of self-harm $[4,5]$. Suggested approaches to reduce pesticide fatalities include phasing out the most toxic products $[6,7]$, introducing pesticide safe storage devices in households [8-10] and teaching safer sales practices to shop keepers[11,12].

However, the development of a sound strategy to reduce access to pesticides is hampered by a lack of knowledge on how people gained access to the pesticides, where pesticides were stored immediately prior to the self-harm attempts and reasons for ingesting particular products. Studies from China [13], India [14] and Sri Lanka [15] found that $65 \%, 80 \%$ and $72 \%$, respectively, of pesticides used for self-harm were obtained from the home or close proximity to home. However, the sample sizes of the above studies were relatively small, so larger studies systematically investigating the storage of pesticides prior to their use for self-poisoning are warranted to aid the development of poisoning prevention strategies.

In this large observational study of patients with pesticide self-poisoning admitted to a district hospital in Sri Lanka, we aimed to determine from where patients obtained the pesticides, the mode of purchase, the place of storage prior to self-poisoning, and why the patients choose the particular pesticide.

\section{Methods}

This study was nested within a larger observational study of poisoning and took place in a secondary referral hospital in Polonnaruwa, Sri Lanka. The Polonnaruwa district is located in the North Central Province where paddy cultivation is predominant and pesticide use is high. The population of the study area is 358, 984 (Male 52.3\%, Female $47.7 \%$ ) [16]. The area is also known for a high burden of pesticide self-poisoning [17].

Our study is based on a series of consecutively admitted self-poisoning patients presenting between June 2004 and
March 2006. Patients were interviewed and examined by trained study doctors who collected epidemiological and clinical data using a standard questionnaire. Patients were asked about the pesticide ingested, storage and accessibility of pesticides immediately prior to the time of selfharm, purpose of purchase of pesticides, and reason for selection of that particular pesticide for the act of selfharm. Patients were interviewed soon after admission if they were conscious and able to participate; patients unwell on admission were interviewed prior to hospital discharge. The interviews were conducted in the ward and in the patient's own language.

Data were entered into an Excel sheet and analyzed using the Statistical Program Stata version 10.1. Pearson Chisquared and Fisher's exact tests were used for analyzing categorical variables.

Ethical approval for this study was obtained from the Ethic Review Committees of the Colombo Medical Faculty, the Sri Lanka Medical Association, the Peradeniya Medical Faculty, and the Australian National University.

\section{Results}

During the 20 month study period, 2019 patients with a history of poisoning were admitted to the adult medical wards of the Polonnaruwa general hospital. Of the 2019 admissions, 1012 (50\%) had ingested a plant, pharmaceutical or household chemical and were excluded from further analysis. A further 125 patients were excluded from the study due to unintentional, homicidal or occupational pesticide exposure $(n=79)$, death before an interview could be conducted $(\mathrm{n}=36)$, referral to tertiary care before interview $(\mathrm{n}=4)$, or being mentally unfit for interview ( $\mathrm{n}=6$ patients).

Therefore, 882 patients were eligible for inclusion in the study. However, 213 interviews were not able to be completed (14 patients refused to participate and interview data were incomplete for 199 patients). Therefore, the analysis includes 669 eligible patients. The patients included in the analysis $(\mathrm{n}=669)$ had lower case fatality (3.7\%, 95\% CI 2.4\%-5.4\%) compared to those eligible patients who didn't complete or participate in the study (n $=213)\left[\left(12.6 \%, 95 \%\right.\right.$ CI 8.5\%-18\%), $\left(\chi^{2}=23.2,1 \mathrm{df}, \mathrm{p}=\right.$ $0.00)]$. Patients who didn't participate in the study were similar in age [median age was 28 (IQR 21-39 years] and gender (66\% males) compared to participants [median age 26 (IQR 20-36; 425 (63.5\%) male]. Forty percent $(40 \%)$ of participants were full time farmers; $20 \%$ did part time farming, while 33\% did another job and $7 \%$ were students. Most of the farmers were male (78\%) while most of the non-farmers were female (58\%). 


\section{Accessibility to pesticide at the time of self-harm}

Forty five percent of patients ingested insecticides $(67 \%$ male, $33 \%$ female), $36 \%$ herbicides (62\% male, $38 \%$ female) and $5 \%$ other pesticides (56\% male, $44 \%$ female) while $14 \%$ ingested unknown pesticides (58\% male, $42 \%$ female). The most popular insecticides were organophosphorus compounds [(69\%), 67\% male, 33\% female] and carbamates [(23\%), 63\% male, 37\% female] while most common herbicides were glyphosate [(27\%), 58\% male, $42 \%$ female] and propanil [(23\%), $48 \%$ male, 52\% female].

Seventy-six percent $(n=511)$ of the pesticides used in the self-harm incident were obtained from a storage place either inside the home $(n=248)$ or just outside it $(n=$ 263), in the home garden (Table 1). Of the pesticides obtained from close to the home, only eight were kept in locked storage. Ten percent $(n=67)$ accessed pesticides that were stored in the field in an open place or hidden under vegetation. Fourteen percent $(n=91)$ patients purchased pesticides from a shop just a few hours prior to pesticide poisoning.

The source of pesticides used for self-harm differed between gender $\left(\chi^{2}=24.8,2 \mathrm{df}, \mathrm{p}=0.000\right)$. Men were more likely to obtain the pesticide from the fields or from a shop; whereas women were more likely to obtain the pesticide from the house or home garden (Table 1). In the study participants who subsequently died in the hospital $(\mathrm{n}=25)$, the sources of pesticides were not different from those who survived $(\mathrm{n}=644)\left[\chi^{2}=0.21,2 \mathrm{df}, \mathrm{p}=0.90\right]$

There was an association between a person's involvement in farming and the source of pesticides used for self-harm $\left[\chi^{2}=10.50,2 \mathrm{df}, \mathrm{p}=0.005\right]$ (table 2). More farmers obtained pesticides from the fields $(52 / 397,13.1 \%)$ than non-farmers $(15 / 272,5.5 \%)$. However, similar proportions of farmers and non-farmers obtained pesticide for self-harm from in or near their home or from a shop.

\section{Purchasing behavior}

About half of the pesticides had been purchased by the patients themselves $[323 / 669,(48 \%)]$ and half had been bought by relatives [346/669, (52\%)]. Most had been bought for cultivation $(533 / 669 ; 80 \%) ; 26 / 669$ (4\%) had been bought for domestic pest control. The remaining pesticides $[110 / 669,(16 \%)]$ had been bought specifically by the patient for the act of self-harm; among this group a subset of 91 patients obtained pesticides only a few hours prior to the poisoning incident. Nineteen patients bought the pesticide for self-harm but stored it in the house for some time (1-2 days) before the act.

\section{Reason for the choice of pesticide for the self-harm}

We asked patients about their main reason for ingesting the particular pesticide. The reasons given were: easy accessibility (311/669 patients, 46\%); popular suicide agent in their village $(290 / 669,43 \%)$; quick action on pests $(25 / 669,4 \%)$, pesticide color (whether the colour of pesticide is dark) or label (labels with dark color) (7/669, $1 \%)$; no reason $(36 / 669,6 \%)$.

\section{Discussion}

This study reaffirms that most pesticides used for selfharm are obtained from the house or its close surrounding $[13,15]$. In addition, the most common reasons for selecting the particular pesticides were easy accessibility and popularity as a suicidal agent in the person's village. These findings are similar to a small study published in the same province which found around $40 \%$ of the pesticide poisoning patients cited easy availability as a main reason for choosing pesticide for self-harm [15]. These findings highlight the importance of accessibility and that measures are needed to ensure safe (locked) storage in and around the home. However, as previous studies found that 24 months after the introduction of safe storage devices only $55 \%$ of households have still made use of the devices [9], it appears unlikely that safe storage will be an effective sole strategy to reduce deaths from pesticide poisoning. Complementary strategies such as reducing the availability of the most highly toxic pesticides through education and regulation need to be explored along with community intervention to provide alternative ways of dealing with stress or reducing other precipitant such as alcohol ingestion [18] or altering the pesticide formulation to reduce the gastrointestinal absorption of pesticides

Table I: Patterns of pesticide storage before self-harm by gender.

\begin{tabular}{llll}
\hline & \multicolumn{2}{c}{ Gender } \\
\cline { 2 - 3 } & Male $(\mathrm{n}=\mathbf{4 2 5 , 6 3 . 5 \% )}$ & Female (n= 244, 36.5\%) & Total (n= 669) (\%) \\
\hline Stored in the field & $50(11.8 \%)$ & $17(7.0 \%)$ & $67(10 \%)$ \\
\hline Stored inside or outside home including in the garden & $299(70.3 \%)$ & $212(86.8 \%)$ & $511(76 \%)$ \\
\hline Obtained from a shop & $76(17.8) \%$ & $15(6.1 \%)$ & $91(14 \%)$ \\
\hline
\end{tabular}


Table 2: Association between types of job and storage of pesticides used for pesticide self-harm.

\begin{tabular}{llll}
\hline & Farmers $(\mathrm{n}=\mathbf{3 9 7 , 6 0 \% )}$ & Non-farmers (n= 272, 40\%) & Total (n= 669) (\%) \\
\hline Stored in the fields & $52(13.1 \%)$ & $15(5.5 \%)$ & $67(10 \%)$ \\
\hline Stored inside or outside home including in the garden & $295(74.3 \%)$ & $216(79.4 \%)$ & $511(76.4 \%)$ \\
\hline Obtained from a shop & $50(12.6 \%)$ & $41(15.1 \%)$ & $91(13.6 \%)$ \\
\hline
\end{tabular}

[19]. Further research on factors such as packaging that could influence the choice of a pesticide for self-harm when it is easily accessible is also important area to be considered.

Our study also shows that about half of non-farmers obtained the pesticides they used for self-harm directly from pesticide outlets, emphasizing the importance of regulating sales practices among both government and private sector. Ninety one patients (14\%) obtained pesticides from the sales outlet just few hours prior to self-poisoning; most of them were young males. A number of studies in the Europe and USA suggested that regulating the sales and pack size of pharmaceuticals may have reduced the number of suicides with pharmaceuticals [2022]. Sri Lanka has effectively regulated the import and use of pesticides in agricultural practice, markedly reducing deaths from self-poisoning [23-25]. The current legislation in Sri Lanka allows for the regulation of sales and marketing and more attention could be given to safe sale practices among the public.

\section{Strengths and Limitations of the study}

The main strength of this study was the large sample size and the ability to collect data soon after self-harm attempt. There are two main limitations. First, we only obtained data from the patients who presented to large referral hospital and this may under-estimate the total number of poisonings in the study area. For example, a number of patients may have died before reaching the hospital, others may have taken small amounts of poison and been managed in peripheral hospitals. Furthermore, we excluded 36 patients from the study as they died soon after admission and a further 213 patients' interviews were incomplete. This may have resulted in a biased assessment of the sources of pesticide used in act of selfharm. However, we didn't find any difference in source of pesticide in participants who died in hospital compared to survivors. Second, we did not investigate the level of intent among these patients; this might have impacted on the way they have accessed the pesticides from a location.

\section{Conclusion}

We found that most people who used pesticides in acts of self-poisoning used chemicals that were already available within the home or in close proximity. This highlights the importance of reducing the accessibility of pesticides in the domestic environment and suggests that it may be possible to reduce deaths from self-poisoning if safe storage practices and proper storage devices are used within farming communities. As it is unlikely that pesticides will always be safely stored, it remains important that the most toxic pesticides continue to be phased out of the market. Further investigation of how the sales of pesticides could be made safer may reduce the number of people with intentions of self harm accessing pesticides from a shop.

\section{Competing interests}

The authors declare that they have no competing interests.

\section{Authors' contributions}

FM involved in collection, processing and analysis of data and wrote the paper, GM and ME are involved in designing the study and revising the manuscript, SA was the visiting physician of the study hospital and supervises the overall recruitment process and helped in data collection, DG and FK involved in statistical analysis and writing the paper and giving guidance to FM on the manuscript writing. AD supervised over all data collection for the study and helped in manuscript writing. All authors contributed to the final version of the manuscript and approve its submission.

\section{Acknowledgements}

We thank SACTRC doctors, directors, medical and nursing staff of the study hospitals for their support and Mr. Steve Bowe for guiding statistical analysis. The work was funded by a Wellcome Trust/NHMRC International Collaborative Research Grant GR07I669MA to SACTRC and a Career Development Fellowship to ME (GR063560MA).

\section{References}

I. WHO: World Health Report 2004, WHO, Geneva; 2004. 2004.

2. Eddleston M: Patterns and problems of deliberate self-poisoning in the developing world. QJM 2000, 93(II):7I5-73I.

3. Gunnell D, Eddleston M, Phillips MR, Konradsen F: The global distribution of fatal pesticide self-poisoning: systematic review. BMC Public Health 2007, 7:357.

4. Gunnell D, Eddleston M: Suicide by intentional ingestion of pesticides: a continuing tragedy in developing countries. Int $J$ Epidemiol 2003, 32(6):902-909.

5. Conner KR, Phillips MR, Meldrum S, Knox KL, Zhang Y, Yang G: Low-planned suicides in China. Psychol Med 2005, 35(8): I 197-1204. 
6. Konradsen F, Hoek W van der, Cole DC, Hutchinson G, Daisley H, Singh S, Eddleston M: Reducing acute poisoning in developing countries--options for restricting the availability of pesticides. Toxicology 2003, 192(2-3):249-26I.

7. Eddleston M, Karalliedde L, Buckley N, Fernando R, Hutchinson G, Isbister G, Konradsen F, Murray D, Piola JC, Senanayake N, et al:: Pesticide poisoning in the developing world--a minimum pesticides list. Lancet 2002, 360(9340): I I63-I I 67.

8. Konradsen F, Pieris R, Weerasinghe M, Hoek W van der, Eddleston $M$, Dawson AH: Community uptake of safe storage boxes to reduce self-poisoning from pesticides in rural Sri Lanka. BMC Public Health 2007, 7:13.

9. Weerasinghe M, Pieris R, Eddleston M, Hoek W, Dawson A, Konradsen F: Safe storage of pesticides in Sri Lanka - identifying important design features influencing community acceptance and use of safe storage devices. BMC Public Health 2008, 8:276.

10. Hawton K, Ratnayeke L, Simkin S, Harriss L, Scott V: Evaluation of acceptability and use of lockable storage devices for pesticides in Sri Lanka that might assist in prevention of self-poisoning. BMC Public Health 2009, 9:69.

II. CropLife International: Guidelines for the safe and effective use of crop protection products. Brussels: Belgium; 1998.

12. FAO: International Code of Conduct on the Distribution and Use of Pesticides. Rome: FAO; 2002.

13. Phillips MR, Yang G, Zhang Y, Wang L, Ji H, Zhou M: Risk factors for suicide in China: a national case-control psychological autopsy study. Lancet 2002, 360(9347): I728-1736.

14. Bose A, Sandal Sejbaek C, Suganthy P, Raghava V, Alex R, Muliyil J, Konradsen F: Self-harm and self-poisoning in southern India: choice of poisoning agents and treatment. Trop Med Int Health 2009.

15. Eddleston M, Karunaratne A, Weerakoon M, Kumarasinghe $S$, Rajapakshe M, Sheriff MH, Buckley NA, Gunnell D: Choice of poison for intentional self-poisoning in rural Sri Lanka. Clin Toxicol (Phila) 2006, 44(3):283-286.

16. Census of population and housing 200I. Department of Census and Statistics, Government of Sri Lanka, Sri Lanka; 2001.

17. Eddleston M, Sheriff MH, Hawton K: Deliberate self harm in Sri Lanka: an overlooked tragedy in the developing world. $B M J$ 1998, 3 I7(7151):133-135.

18. Eddleston M, Buckley NA, Gunnell D, Dawson AH, Konradsen F: Identification of strategies to prevent death after pesticide self-poisoning using a Haddon matrix. Inj Prev 2006, I 2(5):333-337.

19. Wilks MF, Fernando R, Ariyananda PL, Eddleston M, Berry DJ, Tomenson JA, Buckley NA, Jayamanne S, Gunnell D, Dawson A: Improvement in survival after paraquat ingestion following introduction of a new formulation in Sri Lanka. PLOS Med 2008, 5(2): e49.

20. Oliver RG: Rise and fall of suicide rates in Australia: relation to sedative availability. Med J Aust I972, 2(2I): I208-I 209.

21. Hawton K, Townsend E, Deeks J, Appleby L, Gunnell D, Bennewith $\mathrm{O}$, Cooper J: Effects of legislation restricting pack sizes of paracetamol and salicylate on self poisoning in the United Kingdom: before and after study. BMJ 200I, 322(7296): I203-1207.

22. Hawton K, Bergen H, Simkin S, Brock A, Griffiths C, Romeri E, Smith KL, Kapur N, Gunnell D: Effect of withdrawal of co-proxamol on prescribing and deaths from drug poisoning in England and Wales: time series analysis. BMJ 2009, 338:b2270.

23. Roberts DM, Karunarathna A, Buckley NA, Manuweera G, Sheriff $\mathrm{MH}$, Eddleston M: Influence of pesticide regulation on acute poisoning deaths in Sri Lanka. Bull World Health Organ 2003, 8 I (I I):789-798.

24. Manuweera G, Eddleston M, Egodage S, Buckley NA: Do targeted bans of insecticides to prevent deaths from self-poisoning result in reduced agricultural output? Environ Health Perspect 2008, I I 6(4):492-495.

25. Gunnell D, Fernando R, Hewagama M, Priyangika WD, Konradsen F, Eddleston $M$ : The impact of pesticide regulations on suicide in Sri Lanka. Int J Epidemiol 2007, 36(6): I 235-1242.

\section{Pre-publication history}

The pre-publication history for this paper can be accessed here:

http://www.biomedcentral.com/1471-2458/9/405/pre pub
Publish with Bio Med Central and every scientist can read your work free of charge

"BioMed Central will be the most significant development for disseminating the results of biomedical research in our lifetime. "

Sir Paul Nurse, Cancer Research UK

Your research papers will be:

- available free of charge to the entire biomedical community

- peer reviewed and published immediately upon acceptance

- cited in PubMed and archived on PubMed Central

- yours - you keep the copyright

Submit your manuscript here:

http://www.biomedcentral.com/info/publishing_adv.asp
BiolMedcentral 